\title{
Vitamin D and Myofibroblasts in Fibrosis and Cancer: At Cross-purposes with TGF- $\beta$ /SMAD Signaling
}

\author{
SHRAGA SHANY ${ }^{1}$, INA SIGAL-BATIKOFF ${ }^{1,2}$ and SERGIO LAMPRECHT ${ }^{1,2}$ \\ ${ }^{1}$ Department of Clinical Biochemistry and Pharmacology, Faculty of Health Sciences, \\ Ben-Gurion University of the Negev, Beersheva, Israel; \\ ${ }^{2}$ Institute of Gastroenterology and Hepatology, Soroka University Medical Center, Beersheva, Israel
}

\begin{abstract}
The multifaceted involvement of the active vitamin $D$ metabolite 1,25-dihydroxyvitamin $D_{3}$ (henceforth referred to by the synonyms $1,25(\mathrm{OH})_{2} D_{3}$, calcitriol or vitamin $\mathrm{D}$ ) in blunting the growth of cancer cells is amply recognized. In this review we focused our attention on the cross-talk between 1,25 $(\mathrm{OH})_{2} \mathrm{D}_{3}$ and the tumor microenvironment (TME), signaling out stromal cancer-associated fibroblasts (CAFs), the most abundant TME population, as a target for calcitriol anticancer action. In view of the commonality of the phenotypic signature in myofibroblasts, resident in the cancer stroma and in non-neoplastic fibrotic loci, we examined modes of action of vitamin D in non-neoplastic chronic diseases and in cancer to assess mechanistic similarities and divergences. A constant observation was that $1,25(\mathrm{OH})_{2} \mathrm{D}_{3}$ or synthetic ligands via the active vitamin $D$ receptor (VDR) impede transforming growth factor (TGF)-B/mothers against decapentaplegic homologs (SMADs) signaling in myofibroblasts regardless of the initiating insult. The translational impact of $1,25(\mathrm{OH})_{2} \mathrm{D}_{3}$ in targetting stromal CAFs is discussed.
\end{abstract}

\section{Cancer-associated Fibroblasts}

For quite a while, stromal fibroblasts surrounding a growing tumor were considered quiescent bystanders and, consequently, their role in cancer development remained largely neglected. This view has been superseded by a vast body of evidence showing that stromal fibroblasts briskly

This article is freely accessible online

Correspondence to: Professor Sergio Lamprecht, Ph.D., Department of Clinical Biochemistry and Pharmacology, Faculty of Health Sciences, Ben-Gurion University of the Negev, Beersheva, Israel. Tel: 972 86244606, Fax: 972 86479922, e-mail: sergiol@bgu.ac.il

Key Words: Vitamin D, myofibroblast, fibrosis, TGF- $\beta$ /SMAD signaling, review, cancer associated fibroblast, fibrosis. cross-talk with their rogue neighbors and ultimately become partners in crime (1-4). As neoplasia proceeds, fibroblasts are educated by the adjacent cancer cells to foster their growth program and, in their new malevolent vest as activated fibroblasts (hereinafter named myofibroblasts), the nontransformed but pro-tumorigenic cells are properly defined as cancer-associated fibroblasts (CAFs). Of note, CAFs are the most abundant mesenchymal cell population resident in the tumor microenvironment (TME).

We wish at this point to add a note of caution: while a number of studies robustly support the view that heterotypical interactions between CAFs and the tumor cells nurture the neoplastic program (1-4), evidence is available showing that this is not invariably the case as stromal components may act to impede early stage tumorigenesis. In this scenario, the stromal desmoplastic response -the copious secretion by CAFs of collagen fibrils- represents a host defense designed to restrain the growth of the incipient tumor. This view, proposed in early papers by Delinassios working with HeLA cells and human fibroblasts $(5,6)$ has been recently reviewed in detail (7-9).

A comprehensive discussion of how cancer cells corrupt the naïve stromal fibroblasts and impose a multipronged cross-talk with the neighboring mesenchymal cells to foster their neoplastic growth agenda is beyond the main aim of this review and the interested reader is directed to comprehensive reviews (1-4).

\section{The Myofibroblast in Cancer Stroma and in Non-neoplastic Chronic Diseases: A Compelling Phenotypic Commonality}

As mentioned briefly above, one of the principal steps whereby normal stromal fibroblasts acquire the $\mathrm{CAF}$ phenotype is their trans-differentiation to myofibroblasts. Notably, we and others $(10,11)$ have been impressed by the striking similarity in biological behavior and function of the myofibroblast in neoplasia and in a vast range of nonneoplastic chronic diseases that are characterized by extensive 
fibrosis, such as hepatic, renal, cardiac fibrosis, to name but a few. Thus, regardless of the initiating insult, myofibroblasts share common markers like the fibroblast-activation protein and $\alpha$-smooth muscle protein and, importantly, maintain a stable phenotype when severed from the cellular source of their generation $(12,13)$. This phenotypic durability relies on the reprogramming of their epigenetic landscape $(11,14-17)$, a well attested genomic signature in CAFs (18-21).

It is worth noticing at this point that when commenting on the shared biological behavior of myofibroblasts we do not refer to functional identity. Indeed, one may tenably argue that subtle phenotypic changes, as yet unidentified, may distinguish between myofibroblasts from disparate tissue origins. A case in point is represented by the epigenetic change in the Ras protein activator like 1 (RASAL-1) gene in kidney, cardiac and hepatic myofibroblasts resident in fibrotic areas $(22,23)$. RASAL1 is a gene encoding a GAP/GTPase involved in the normal, finely-tuned regulation of $K R A S$ signaling (24). In cells bearing RASALl with the changed epigenetic signature, the $K R A S$ gene does act constitutively because of promoter hypermethylation and silencing of the key RASAL-1 GTPase activity. We wish to remark here that the RASAL- 1 finding signifies that a stable genomic change in myofibroblasts may occur at regulatory sites of gene expression and not necessarily impinge on the epigenetic landscape of a gene that appears deceptively "wild" and unscathed in function. The RASAL-1 genomic change, found also in epithelial tumors $(25,26)$, has not been observed (or not searched for) in stromal CAFs. Our preliminary studies have been inconclusive (data not shown).

With the above note of caution in place, the evidence showing similar biological functions in myofibroblasts in fibrotic loci or in cancer stroma is robust, reminding us that cancer is "a wound that never heals" (27), a perpetual lesion that, ultimately, morphs into a tumor.

Taking into account the commonality of biological behavior and function of myofibroblasts of disparate origins, one can tenably argue that CAFs respond to calcitriol challenge similarly to non-neoplastic myofibroblasts resident in fibrotic loci. Since the body of findings pertaining to $1,25(\mathrm{OH})_{2} \mathrm{D}_{3}$ and its antifibrotic action is vast compared to the present scarce, but briskly evolving, knowledge of a putative effect of calcitriol on the cancer stroma, we believe that the harness of findings and careful interrogation of molecular events imposed by vitamin D on the non-neoplastic myofibroblast is central to gain additional insight into $1,25(\mathrm{OH})_{2} \mathrm{D}_{3}$ modes of action when the stromal $\mathrm{CAF}$ is the target cell and cancer is the main issue of interest.

\section{Transforming Growth Factor- $\beta$ (TGF- $\beta$ ): A Master Driver of Fibrogenesis}

TGF- $\beta$ is undeniably one of key drivers of fibrogenesis $(28,29)$. Before further addressing this issue, a brief description of the TGF- $\beta$ signaling pathway, simplified as a linear pathway, is warranted. Following TGF- $\beta$ binding to cognate receptors, a cascade of intracellular events leads to phosphorylation of cytosolic protein effectors, dubbed mothers against decapentaplegic homologs (SMADs). The activated SMADs (also referred to as R-SMADs) form an oligomeric complex with SMAD4, the obligatory promiscuous R-SMAD carrier, and translocate to the nucleus where they recruit co-activators, such as the histone acetylase p300 and co-repressors, provoking changes in chromatin architecture $(30,31)$. Nuclear R-SMADs as bona fide transcription factors interact with cis-based elements in the regulatory regions of an extensive number of target genes, including pro-fibrotic genes (Figure 1A) (30-32).

The up-regulation of pro-fibrotic genes expression by the TGF- $\beta$ /SMAD pathway is well-documented. An interesting paper (33) has shown that, in human skin fibroblasts, TGF- $\beta 1$ acting via SP1 and the SMAD3 pathway induces the expression of procollagen lysyl hydroxylase 2 (PLOD2), a gene coding for an enzyme that specifically catalyzes the hydroxylation of collagen lysine residues resulting in increased tissue stiffness, a potent stimulus for myofibroblast differentiation $(34,35)$. TGF$\beta$ also up-regulates in lung fibroblasts lysine oxidases $(36,37)$, key enzymes involved in the covalent cross-linking of collagen molecules essential for collagen maturation and deposition (38) and the modulation of TME mechanical properties. Predictably, the busy cytokine up-regulates in cardiac fibroblasts the expression of collagen COL1A1, an abundant protein in fibrosis and in cancer desmoplasia (39).

The mechanistic involvement of the TGF- $\beta$ /SMAD pathway in fibrogenesis has been forcefully demonstrated in SMAD3null mice that are resilient to experimental fibrosis (40).

In addition to its role as a prototypical pro-fibrotic driver, TGB- $\beta$ induces fibroblast-to-myofibroblast trans-differentiation acting on normal stromal fibroblasts, on fibroblasts surrounding the incipient tumor or in non-neoplastic chronic diseases, such as rheumatoid arthritis, liver fibrosis, kidney fibrosis or systemic sclerosis (41-44), to name but a few.

\section{Vitamin D and Fibrosis}

Vitamin D has been extensively studied as an anti-fibrotic agent in non-neoplastic chronic diseases and a number of studies have shown that the myofibroblast is a main target cell of $1,25(\mathrm{OH})_{2} \mathrm{D}_{3}$ inhibitory action (reviewed in 45,46$)$. A main and recurring finding has been that $1,25(\mathrm{OH})_{2} \mathrm{D}_{3}$ interferes with the pervasive pro-fibrotic action of TGF- $\beta$ : this inhibitory effect is predictable since calcitriol, on its own, represses collagen synthesis in a variety of cells $(47,48)$.

We have selected liver fibrosis as a paradigm of a chronic disease to gain additional insight into molecular modes of action of $1,25(\mathrm{OH})_{2} \mathrm{D}_{3}$. A major determinant of liver fibrosis is the reprograming of quiescent hepatic stellate cells by TGF $\beta$-1/SMADs signaling to a myofibroblast-like phenotype producing excessive extracellular matrix (ECM) components 


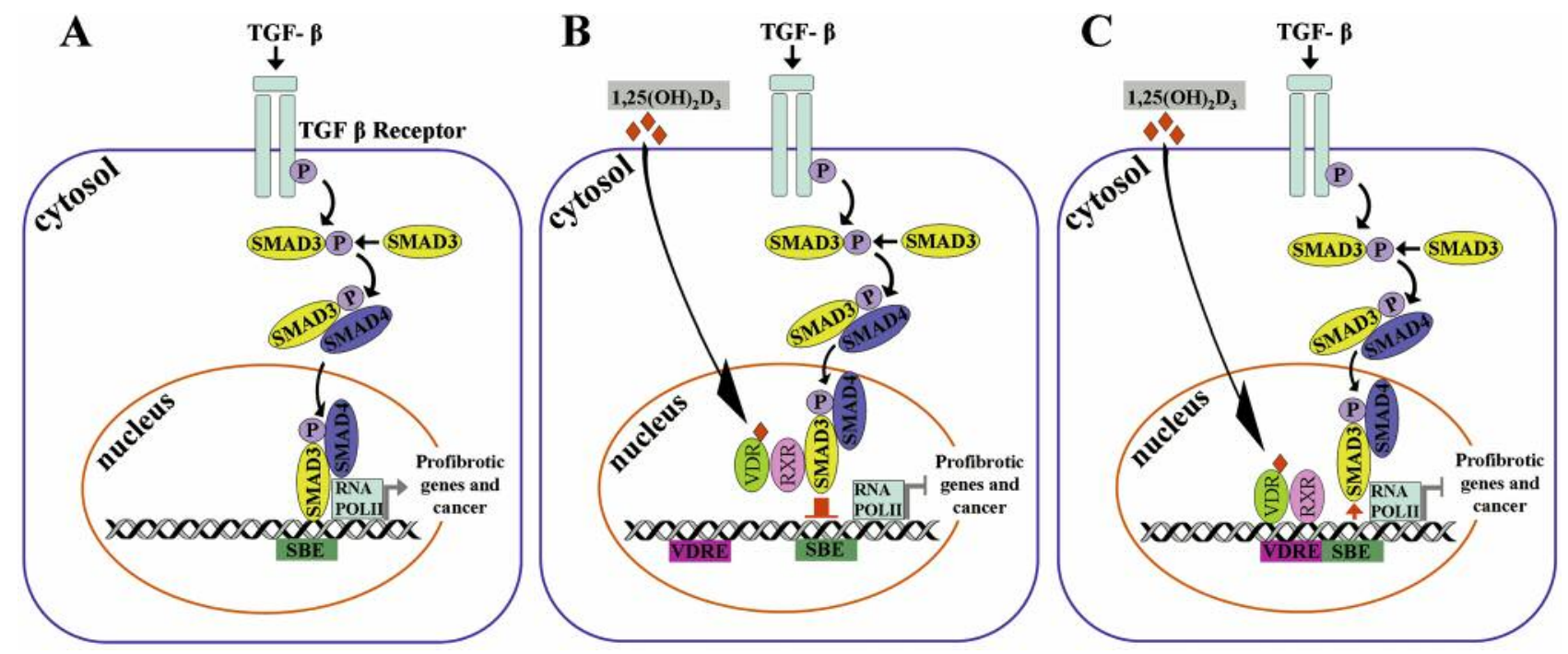

Figure 1. Modes of transcriptional action of $1,25(\mathrm{OH})_{2} \mathrm{D}_{3} / V D R$ in impeding the pro-fibrotic, pro-tumorigenic effect of TGF- $\beta$ in CAFs (based on and modified from References 51,65, 67, 70). A: TGF- $\beta$ signaling via nuclear SMAD3 up-regulates a pro-fibrotic, pro-tumorigenic phenotype in CAFs. B: VDR impedes TGF- $\beta$ signaling by binding to SMAD3. C: VDR blunts TGF- $\beta$ signaling by genomic competition dislodging SMAD3 from SBE. 1,25(OH) ${ }_{2} D_{3}, 1,25$-dihydroxyvitamin D3; TGF- $\beta$, transforming growth factor- $\beta$; CAFs, cancer-associated fibroblasts; SMAD, mothers against decapentaplegic homolog; VDR, vitamin D receptor; VDRE, vitamin D response element; SBE, SMAD binding element.

$(49,50)$. Hepatic stellate cells are resident, non- parenchymal, perisinusoidal cells in the liver rich in vitamin A esters and endowed with a large range of biological function $(49,50)$.

In a hallmark paper, Ding et al. (51), using the carbontetrachloride mouse model of human liver fibrosis, reported that co-treatment with calcipotriol, a synthetic vitamin D receptor (VDR) agonist, resulted in a reduction in fibrotic scores, collagen deposition and decreased expression of genes involved in the process of fibrogenesis, such as COL1A1, $T I M P 1$ and $T G F \beta-1$. Interestingly, pretreatment with the synthetic vitamin D analogue before administration of the hepatoxic agent resulted in nearly complete abrogation of fibrosis. The active involvement of $V D R$ in restraining fibrogenesis was strengthened by the observation that VDR knockout mice spontaneously developed hepatic fibrosis.

Exposure of a primary rat hepatic stellate cell line to vitamin $D$ resulted in marked down-regulation the expression of a large number of TGF $\beta$-1-induced pro-fibrotic genes. Importantly, the combination of chromatin immunoprecipitation with high throughput deep-sequencing for identification of genome -wide binding sites in the LX-2 HSC cell line exposed to calcipotriol, vis-à-vis control samples, revealed that the binding sites for VDR and SMAD3 were greatly enhanced and within a nucleosome distance, suggesting a close proximity of the respective cistromes. Indeed, ChiP-on-ChiP analysis revealed that both VDR and SMAD3 were located in the same binding sites. The authors proposed that the VDR/RXR heterodimer interferes with TGF $\beta$-1/SMAD3 transcriptional up-regulation of pro-fibrotic genes by antagonizing SMAD3 binding to their cognate response elements (Figure 1C).This genomic competition was made possible by TGF $\beta$-1-dependent chromatin remodeling, which disclosed a large number of "cryptic" VDR binding sites. This change in chromatin structure was triggered by histone acetylation, a post-translation modification in histone tails that is associated with an open, transcriptionally active chromatin (52). A predominant candidate involved in this process would be acetyltransferase $\mathrm{p} 300$, a key transcriptional TGF- $\beta$ co-activator: of note, p300 is robustly expressed in normal fibroblasts and in myofibroblasts in fibrosis $(53,54)$. These mechanistic events ultimately provoked a redistribution of genome-wide VDR binding sites (frequently referred to as the VDR cistrome) very close to SMAD3 binding response elements. The overlapping access to DNA and the occupancy by VDR dislodged SMAD3 from the chromatin site and interfered with the pro-fibrotic action of TGF $\beta-1$. Put differently, TGF- $\beta$ unwittingly brings VDR uncomfortably close to cis-regulatory sequence of SMAD3-responsive genes (Figure 1C).

These results are consistent with previous findings showing that vitamin D exhibits an anti-fibrotic effect in rat hepatic stellate cells via interference with collagen $1 \alpha$ promoter activity (55). In this study, it was also shown that $1,25(\mathrm{OH})_{2} \mathrm{D}_{3}$ induces an anti-fibrotic phenotype by up-regulating the expression of MMP8, a metalloproteinase that degrades collagen.

In view of Ding et al.'s findings (51), it is pertinent at this point to pause and briefly review what it is presently known about the transcriptional activity of VDR. A large body of 
evidence supports the view that the active VDR, once bound to $1,25(\mathrm{OH})_{2} \mathrm{D}_{3}$ or to synthetic vitamin $\mathrm{D}$ analogs, translocates to the cell nucleus and forms an obligate heterodimer with the retinoid X receptor ( $\mathrm{RXR})$. The VDR/RXR heterodimer, once positioned at vitamin $\mathrm{D}$ response element (VDRE), directs the recruitment of nuclear co-activators proteins, e.g. histone acetytransferases and co-repressors (Figure 1B) $(56,57)$. Epigenetic changes induce looping of VDR-responsive genomic regions toward the transcription initiation site. The VDR cistrome is highly dynamic and binds to enhancers frequently located in intergenic regions and introns separated by considerable distances from the transcription start site of target genes (57-60).

Acting as a transcription factor, VDR/RXR governs the expression of a large number of genes, and the propensity of VDR to interact with and bind to a vast number of transcription factors to up-regulate or repress gene expression is well-documented $(56,57,61)$. Interacting transcription factors include the potent pro-inflammatory nuclear factor-kB (NF-kB) (62) and the growth factor epidermal growth factor (EGF) (63), to name but a few. One of recent findings is the interaction of VDR with nuclear $\beta$-catenin (64), a physical connection that impedes the pro-fibrogenetic and oncogenic signaling of the Wnt pathway.

With this background in mind, we can now better appreciate the new mode of VDR action described above in transcriptionally interfering with TGF- $\beta$ signaling activity, based not on direct binding of the VDR to SMADs but on genomic competition with adjacent transcription factors of SMADs (Figure 1C). As pointed out previously (65), the competitive inhibition of SMADs transcriptional activity by VDR is substantially different from cystromic interactions between transcription factors resulting on mutual exclusion (66).

A number of independent papers reveal that the propensity of VDR and SMADs, in particular SMAD3, to directly or indirectly intersect is not restricted to hepatic fibrosis. This was shown in TGF- $\beta$-activated skin isolated fibroblasts of patients and in experimental murine models of systemic sclerosis, a chronic disease characterized like hepatic fibrosis by excessive accumulation of ECM components (67). Using reporter assays, target gene analyses and coimmunoprecipitation, these investigators reported that paricalcitol, a synthetic VDR ligand, inhibited fibrogenesis induced by SMAD3 transcriptional gene activation via the binding of VDR to phosphorylated SMAD3, an anti-fibrotic mechanism obviously different from genome competition discussed above (Figure 1B).This repressive action reduced the stimulatory effect of TGF- $\beta$ on collagen release and myofibroblastic differentiation. Of note, $1,25(\mathrm{OH})_{2} \mathrm{D}_{3}$ was shown to prevent TGF $\beta$-1-dependent pro-fibrotic changes in human primary cardiac fibroblasts (68): the interference with TGF- $\beta$ downstream signaling appears to result from marked inhibition of SMAD2 phosphorylation due to interaction of calcitriol with cytosolic SMAD2. It remains unclear, however, which molecular requirements underpin the interaction of vitamin D with SMAD2 in the cell cytosol.

While the diverse modes of VDR-SMAD interaction await explanation, possibly reflecting diverse cellular contexts, all of them ultimately lead to the identical final result: downregulation of TGF- $\beta$-induced nuclear SMAD3 transcriptional activity by $1,25(\mathrm{OH}) 2 \mathrm{D} 3$ and the consequent blunting of TGF$\beta$ signaling.

The importance of TGF- $\beta$, as a main driver of fibrosis, has been emphasized in this review in the context of its cross-talk with vitamin D. However, additional mechanisms and pathways of fibrosis are well-known and the interested readers should peruse excellent reviews on this arresting issue $(12,69)$.

\section{Vitamin D and Stromal CAFs}

Fortified from the perusal of these findings, we now address the question whether vitamin $D$ interferes with the action of TGF- $\beta$ in CAFs via similar mechanistic routes efficiently used in blunting the cytokine activity in non-neoplastic myofibroblasts. This query has been recently experimentally addressed. In a hallmark study, Shermann and colleagues (70) showed that, by targeted remodeling of mouse TME in pancreatic cancer, vitamin D improves drug delivery without interfering with the beneficial action that intact stroma exerts on pancreatic tumors. Notably, calcitriol previously shown to induce quiescence in pancreatic stellate cells, the precursors of pancreatic myofibroblasts (49), reprograms the stromal phenotype to one that is not inflammatory and quiescent.

Interestingly, the assessment of whether VDR/SMAD genomic competition, noted in myofibroblasts in hepatic fibrosis, is also operative in pancreatic stellate cells provided interesting results: calcitriol challenge resulted in decreased SMAD3 binding to promoter regions of pro-fibrotic genes, such as HAS2 (encoding a ECM proteoglycan component) and COLIAI (encoding the predominant component of collagen), indicating a similar anti-fibrotic action by pancreatic CAFs as shown in myofibroblasts resident in nonneoplastic fibrotic loci. Moreover, in an allograft orthotopic mouse model of pancreatic cancer, intraperitoneal administration of calcitriol in combination with the widely used chemotoxic drug gemcitabine increased the intratumoral concentration of gemcitabine, decreased pancreatic tumor volume and, importantly, markedly increased survival compared to chemotherapy alone. The mechanistic involvement of VDR in inducing fibrosis was again evident in the observation that $V D R$-null mice showed periacinar and periductal fibrosis. These findings have been reviewed and commented in a number of papers $(65,71)$.

What is, however, the relevance of the pancreatic cancer studies involving activated VDR and the stroma with respect to other solid malignancies characterized by a strong 
desmoplastic reaction? Does the $1,25(\mathrm{OH})_{2} \mathrm{D}_{3} / \mathrm{VDR}$ duo interfere with the TGF- $\beta$ /SMADs pathway or is this inhibitory action a peculiarity restricted to pancreatic cancer, as noted for the protective stroma?

\section{Vitamin D, TGF-ß/SMAD Signaling and CAFs in Colorectal Cancer}

We have selected colorectal cancer (CRC) as a paradigm to probe the above questions and focused on the TGF $\beta /$ SMADs transduction pathway and on vitamin $\mathrm{D}$ treatment during the typical adenoma-carcinoma sequence in CRC.

A large number of studies show that mutational inactivation of key component of the TGF- $\beta$ signaling pathway is predominant during sporadic CRC progression, impinging on TGF- $\beta$ receptors or on SMAD intracellular mediators, such as SMAD4, SMAD2 and SMAD3 $(72,73)$. Genomic changes in the TGF- $\beta$ pathway are first observed in advanced adenomas (74). These changes obliterate the anti-growth action of the cytokine acting as a tumor suppressor gene at early stages of tumorigenesis (31). Intriguingly, however, $T G F-\beta$ or $S M A D$ mutant CRC cells retain their capacity of abundant TGF- $\beta$ production. There is here an interesting conundrum: What is the selective advantage of cancer cells to produce a potent growth factor bereft of the cognate, responsive receptor? It has been shown that opportunistic tumor cells with a disabled TGF- $\beta$ receptor exploit their own unimpaired synthesis of TGF- $\beta$ by using the cytokine for the paracrine delivery of signals to CAFs that are endowed with a wild TGF- $\beta$ receptor and an unimpaired SMAD downstream pathway. In turn, challenged CAFs respond with the production of pro-tumorigenic growth factors and interleukins acting on the cancer cells, a vicious circuitous route that ultimately sustains and reinforces their relentless oncogenic program (75). Importantly, CAFs automatously synthesize and secrete copious amounts of TGF$\beta$, thus generating an autocrine loop that sustains the fibroblastmyofibroblast trans-differentiation process (76) with expansion of their own population. The reader, eager for additional details pertaining to TGF- $\beta$ mechanistic involvement in the CAFdriven colonic neoplasia, is directed to a recent excellent review by Calon et al. (77).

In a recent paper, Calon et al. (78) observed that CRC subtypes displaying resistance to therapy and poor diagnosis are characterized by genes expressed predominantly in stromal cells, particularly in CAFs, rather than in epithelial tumor cells. Bioinformatics and immunohistochemical assays identified stromal markers that were indicative of disease relapse in the CRC types. Moreover, CAFs were shown to increase the frequency of tumor-initiating cells and this effect was markedly enhanced by TGF- $\beta$ signaling derived from cancer cells. All poor prognosis CRC subtypes were shown to exhibit the same gene program induced by TGF- $\beta$ in stromal cells. Moreover, CRC patients'-derived organoids and xenografts showed that the use of an inhibitor acting on the TGF- $\beta$ receptor, thus blocking the malevolent cross-talk between colorectal cancer cells and the stromal cytokine described above, resulted in impeding disease progression. Predictably, pharmacological silencing of the TGF- $\beta$ receptor affected only the stromal cells. In a parallel work, Isella et al. (79) showed that the CRC transcriptome is mostly derived from stromal CAFs.

Notably, likewise in CRC, TGF- $\beta$ signaling is silenced in a large number of tumor pancreatic cancers, particularly by mutations affecting SMAD 4, the mandatory conveyor of RSMADs into the cell (80). In these mutant cells, transport of R-SMADs into the nucleus comes to a standstill. A tenable possibility is that pancreatic adenocarcinoma cells devoid of TGF- $\beta$ signaling communicate with CAFs via cancer-derived TGF- $\beta$ exploiting the vicious circuitous route experimentally described in CRC.

Having ascertained that TGF- $\beta$ signaling from CAFs is a main motive in driving $\mathrm{CRC}$, we turn now to $1,25(\mathrm{OH})_{2} \mathrm{D}_{3}$ and its anticancer effect on CRC. A number of studies have shown that vitamin $\mathrm{D}$ is effective in blunting colonic carcinogenesis in animal models (81) and various lines of evidence, but not all, indicate that vitamin D deficiency is associated with increased risk of colonic cancer (82-84). Findings have shown that VDR is down-regulated in a proportion of human colonic carcinomas, thus limiting the use of $1,25(\mathrm{OH})_{2} \mathrm{D}_{3}$ treatment to adenomatous stages in CRC.

A recent paper by Ferrer-Mayorga and collegues (85) adds new interesting results to this issue. These investigators observed that a high VDR density in CAFs is associated with longer survival in a large cohort of CRC patients independently of its expression in adenocarcinoma cells. Patient-derived colonic CAFs expressed VDR and responded to $1,25(\mathrm{OH})_{2} \mathrm{D}_{3}$ with the inhibition of CAF pro-migratory effects on cancer cells and of collagen contraction, a major hallmark of myofibroblast activity. Moreover, vitamin D was shown to modulate CAFglobal gene expression program inducing a gene signature that afforded a favorable clinical outcome in CRC patients. Cumulatively, these results indicate that $1,25(\mathrm{OH})_{2} \mathrm{D}_{3}$ exerts protective effects against CRC via the regulation of CAF expression and action and, moreover, suggest that a putative therapeutic action of VDR ligands may be extended to a cohort of patients with CRC at advanced stages of the disease.

Notwithstanding the recurring observation that vitamin D restrains the progression of CRC and the pervasive involvement of TGF- $\beta$ in this neoplastic process, there is a surprising dearth of studies exploring the possibility that $1,25(\mathrm{OH})_{2} \mathrm{D}_{3}$ exerts anticancer action by interfering with TGF- $\beta$ /SMADs signaling in CRC. Thus, the mechanistic "convergence" between the calcitriol and the cytokine shown in fibrosis and in pancreatic cancer remains to be established. However, on the strength of the cumulative results discussed above, we hold the tenable view that one of the main 
A
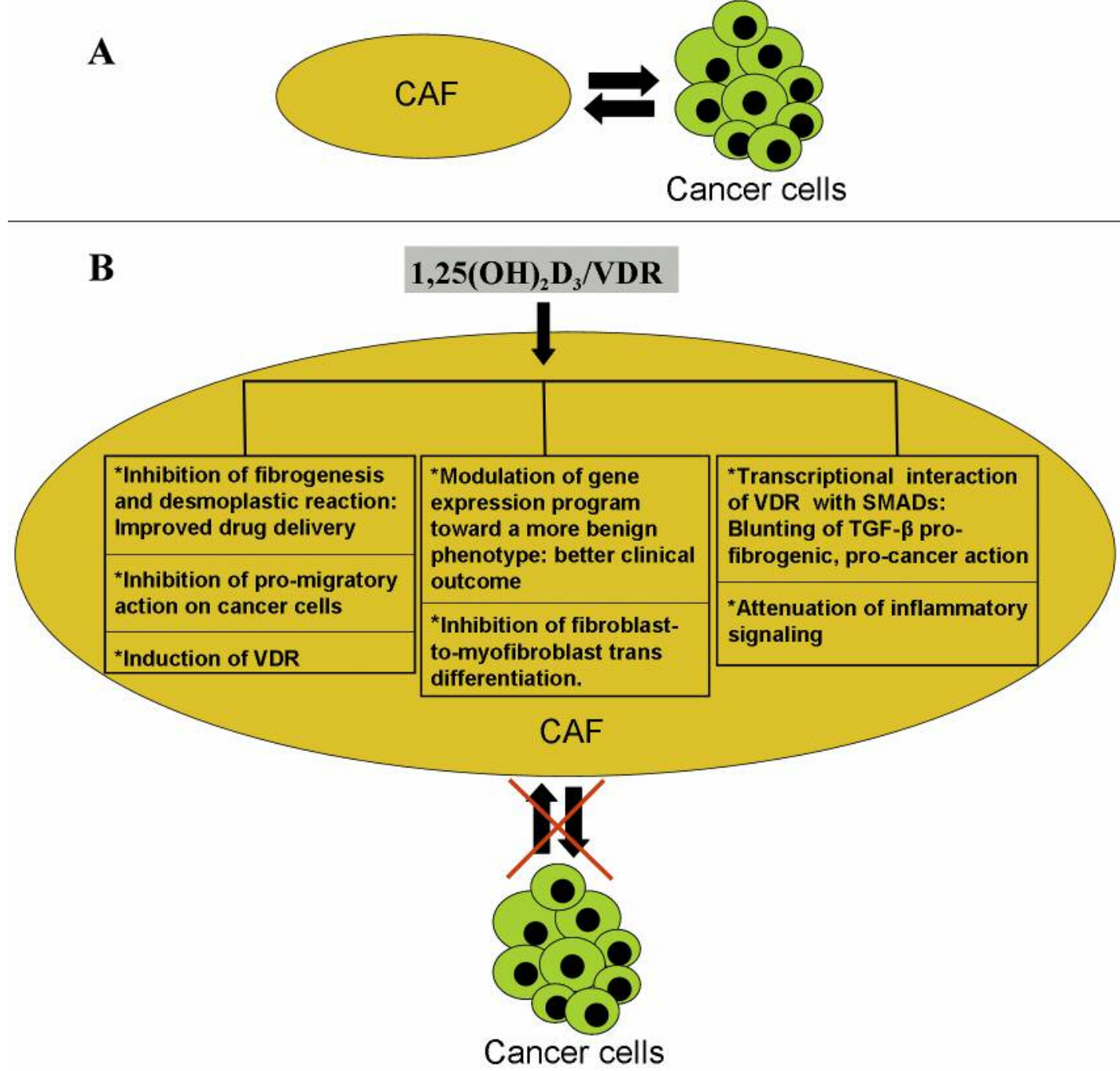

Figure 2. 1,25( $\mathrm{OH})_{2} D_{3} / V D R$ induced anticancer action in CAFs. A: Schematic representation of the stimulatory self-sustaining cross-talk between CAFs and cancer cells. B: Cellular and molecular events induced by vitamin $D$ in CAFs blunting their pro-tumorigenic action. Details of transcriptional interactions of VDR with SMADs are shown in Figure 1.1,25(OH ${ }_{2} D_{3}, 1,25$-dihydroxyvitamin $D_{3}$; VDR, vitamin D receptor; CAFs, cancer-associated fibroblasts; SMADs, mothers against decapentaplegic homologs.

anticancer effects of calcitriol on CRC malignant cells resides in the interference with the TGF- $\beta$-activated pathway in colonic CAFs, thus interrupting the vicious pro-tumorigenic circle sustained by the paracrine delivery of cancer-derived TGF- $\beta$. VDR could act by impeding SMAD transcriptional action either by binding to SMADs or by genomic competition as found in stromal pancreatic adenocarcinoma cells or in myofibroblasts in fibrotic loci (Figure 1B and C).

Figure $2 \mathrm{~B}$ shows routes of $1,25(\mathrm{OH})_{2} \mathrm{D}_{3} / \mathrm{VDR}$ action in inducing a more benevolent phenotype in stromal CAF, which, in turn, results in the disruption of the growth program of neighboring tumor cells.

\section{Conclusion}

The recognized commonality in the phenotype of the myofibroblasts and their biological response in tumors and fibrotic loci should be not surprising considering that unresolved, chronic inflammation is the original $\sin$ responsible for driving both fibrosis and cancer (86-92).

Neoplastic cells trigger an inflammatory response that builds up a pro-tumorigenic microenvironment and upregulates the inflammatory profile of stromal fibroblasts (93). In addition, CAFs maintain the inflammatory TME by expressing a frank pro-inflammatory gene signature and by 
acting as brisk recruiters of pro-inflammatory cells Importantly, CAFs produce pro-inflammatory factors that reinforce and maintain stromal inflammation (94-97). Frequently, the same pro-inflammatory cytokines, e.g. IL-6, IL-11, are produced by cancer and stromal cells. Therefore, in a vicious circular train of events, both tumor cells and CAFs contribute to the TME inflammasome (Figure 2A).

One of the pivotal inflammatory transcription factors is NF$\mathrm{kB}$, a family of dimeric transcription factors expressed in CAFs (96) with a cardinal role in the regulation of immune responses, inflammation and cancer (98). We have mentioned briefly before that $1,25(\mathrm{OH})_{2} \mathrm{D}_{3}$ inhibits NF-kB activation and signaling via its "messenger VDR" by acting on several components of the multifaceted NF-kB system $(62,99)$. It is worth noticing that previous works have shown that fibroblasts lacking the vitamin $\mathrm{D}$ receptor exhibit increased NF-kB activity $(100,101)$. Obviously, an additional mechanistic route, whereby vitamin $\mathrm{D}$ interferes with $\mathrm{CAF}$ protumorigenic purposes, is by blunting their potent NF-kB proinflammatory signaling.

While previous studies pertaining to drug-related therapeutic response and resistance were centered on the tumor cell, accruing evidence that TME is intimately involved in promoting the neoplastic process makes, the identification and characterization of drugs interfering with the brisk stroma-tumor dialogue a cardinal aim of translational and clinical oncology. Targeting of stromal TME pro-tumorigenic components, such as CAFs, is presently under intense interrogation.

As outlined previously, ablation of pancreatic stroma is associated with worsening of the cancer progress. However, irrelevant of whether cancer stroma is protective or cancerpromoting, the tumor dense fibrotic desmoplastic reaction may greatly impair the therapeutic efficacy of a drug by limiting or blocking its delivery, thus imposing a serious therapeutic impasse.

The type of therapeutic stromal resistance, which provides a sanctuary for cancer cells from cytotoxic agents, is obviously different from tumor intrinsic or adaptive resistance to chemotherapy and molecularly targeted therapy (102). The active participation of TME in the regulation of therapeutic response in neoplasia has been incisively reviewed (103).

We and others (104-107) hold the tenable opinion that, in contrast to the ablation and loss of stromal components (108), the reprogramming and re-education of specific TME cell populations, such CAFs, are obviously the most logical and less disrupting approaches to selectively modify TME: in this context, vitamin D reprogramming of the pancreatic stroma (70) by promoting the dedifferentiation of hepatic stellate cells is a salient case in point. Another pertinent example is the reprograming of TME by disruption of the $\mathrm{C}-\mathrm{C}$ chemokine receptor type 5 (CCR5)induced homing of regulatory $\mathrm{T}$ cells in a mouse pancreatic ductal adenocarcinoma model (109). This inhibitory action, associated with reprograming of TME to support antigen presentation, may improve the efficacy of checkpoint-based immunotherapy.

The evidence for targeting specific TME components, in general, and CAFs, in particular, as a valid approach to an antitumor treatment rests on sound logic: we believe, however, that drug interventions, aimed to the complex and intimate tumor-stroma liaison or to a single stromal cell population, will not lead to tumor banishment but, at best, to restraining and quenching the relentless tumorigenic drive. A combinatorial strategy impinging on both cancer cells and their rogue mesenchymal neighbors should, therefore, be an integral part of treatment protocols focused on interfering with cancer development. In this context, $1,25(\mathrm{OH})_{2} \mathrm{D}_{, 0}$, acting on both cancer epithelial cells and stromal TME components, such CAFs, is well-qualified not only as an adjuvant treatment but also as a potential dual benefit drug.

In this review, the active VDR occupies a key mechanistic role acting on the myofibroblast chromatin. A decade ago, we published an editorial (110) on the mechanism of vitamin D. Many unresolved questions raised at that time, such as the functional relationships between VDR and histone posttranslational modifications, as well as the temporal order of VDR co-factors recruitment at the VDRE, have been answered. Other questions, to date, await explanation and are the focus of intense investigation.

\section{Conflicts of Interest}

The Authors have no conflicts of interest to declare.

\section{References}

1 Kalluri R: The biology and function of fibroblasts in cancer. Nat Rev Cancer 16: 582-598, 2016.

2 Öhlund D, Elyada E and Tuveson D: Fibroblast heterogeneity in the cancer wound. J Exp Med 211: 1503-1523, 2014.

3 Polanska UM and Orimo A: Carcinoma-associated fibroblasts: Non-neoplastic tumour-promoting mesenchymal cells. J Cell Physiol 228: 1651-1657, 2013.

4 Madar S, Goldstein I and Rotter V: 'Cancer associated fibroblasts' - more than meets the eye. Trends Mol Med 19: 447453, 2013.

5 Delinassios JG: Fibroblasts against cancer cells in vitro. Anticancer Res 7: 1005-1010, 1987.

6 Delinassios JG: Cytocidal effects of human fibroblasts on HeLa cells in vitro. Biol Cell 59: 69-77, 1987.

7 Angeli F, Koumakis G, Chen M, Kumar S and Delinassios JG: Role of stromal fibroblasts in cancer: Promoting or impeding? Tumour Biol 30: 109-120, 2009.

8 Bissell MJ and Hines WC: Why don't we get more cancer? A proposed role of the microenvironment in restraining cancer progression. Nat Med 17: 320-329, 2011.

9 Delinasios JG, Angeli F, Koumakis G, Kumar S, Kang W, Sica G, Iacopino F, Lama G, Lamprecht S, Sigal-Batikoff I, Tsangaris 
GT, Farfarelos CD, Farfarelos MC, Vairaktaris E, Vassiliou S and Delinasios GJ: Proliferating fibroblasts and HeLa cells cocultured in vitro reciprocally influence growth patterns, protein expression, chromatin features and cell survival. Anticancer Res 35: 1881-1916, 2015.

10 Rybinski B, Franco-Barraza J and Cukierman E: The wound healing, chronic fibrosis, and cancer progression triad. Physiol Genomics 46: 223-244, 2014.

11 Yao $\mathrm{H}$ and Li J: Epigenetic modifications in fibrotic diseases: Implications for pathogenesis and pharmacological targets. J Pharmacol Exp Ther 352: 2-13, 2015.

12 Wynn TA and Ramalingam TR: Mechanisms of fibrosis: Therapeutic translation for fibrotic disease. Nat Med 18: 10281040, 2012

13 Balestrini JL, Chaudhry S, Sarrazy V, Koehlera A and Hinz B: The mechanical memory of lung myofibroblasts. Integr Biol (Camb) 4: 410-421, 2012.

14 Cribbs A, Feldmann $\mathrm{M}$ and Oppermann U: Towards an understanding of the role of DNA methylation in rheumatoid arthritis: Therapeutic and diagnostic implications. Ther Adv Musculoskel Dis 7: 206-219, 2015.

15 Frank-Bertoncelj $\mathrm{M}$ and Gay S: The epigenome of synovial fibroblasts: An underestimated therapeutic target in rheumatoid arthritis. Arthritis Res Ther 16: 117, 2014.

16 Klein K and Gay S: Epigenetic modifications in rheumatoid arthritis, a review. Curr Opini Pharmacol 13: 420-425, 2013.

17 Tampe B and Zeisberg M: Evidence for the involvement of epigenetics in the progression of renal fibrogenesis. Nephrol Dial Transplant 29: i1-i8, 2014.

18 Gonda TA, Varro A, Wang TC and Tycko B: Molecular biology of cancer-associated fibroblasts: Can these cells be targeted in anti-cancer therapy? Semin Cell Dev Biol 21: 2-10, 2010.

19 Jiang L, Gonda TA, Gamble MV, Salas M, Seshan V, Tu S, Twaddell WS, Hegyi P, Lazar G, Steele I, Varro A, Wang TC and Tycko B: Global hypomethylation of genomic DNA in cancerassociated myofibroblasts. Cancer Res 68: 9900-9908, 2008.

20 Vizoso M, Puig M, Carmona FJ, Maqueda M, Velásquez A, Gómez A, Labernadie A, Lugo R, Gabasa M, Rigat-Brugarolas LG, Trepat X, Ramírez J, Moran S, Vidal E, Reguart N, Perera A, Esteller M and Alcaraz J: Aberrant DNA methylation in non-small cell lung cancer-associated fibroblasts. Carcinogenesis 36: 1453-1463, 2015.

21 Ling E, Ringel A, Sigal-Batikoff I, Abu-Freha N, Vaknine H, Friah W, Reshef A, Pinsk I, Fich A and Lamprecht S: Human colorectal cancer stage-dependent global DNA hypomethylation of cancerassociated fibroblasts. Anticancer Res 36: 4503-4508, 2016.

22 Xu X, Tan X, Tampe B, Nyamsuren G, Liu X, Maier LS, Sossalla S, Kalluri R, Zeisberg M, Hasenfuss G and Zeisberg EM: Epigenetic balance of aberrant Rasal1 promoter methylation and hydroxymethylation regulates cardiac fibrosis. Cardiovasc Res 105: 279-291, 2015.

23 Bechtel W, McGoohan S, Zeisberg EM, Müller GA, Kalbacher H, Salant DJ, Müller CA, Kalluri R and Zeisberg M: Methylation determines fibroblast activation and fibrogenesis in the kidney. Nat Med 16: 544-550, 2010.

24 Allen M, Chu S, Brill S, Stotler C and Buckler A: Restricted tissue expression pattern of a novel human rasGAP-related gene and its murine ortholog. Gene 218: 17-25, 1998.

25 Liu D, Yang C, Bojdani E, Murugan AK and Xing M: Identification of RASAL1 as a major tumor suppressor gene in thyroid cancer. J Natl Cancer Inst 105: 1617-1627, 2013.
26 Ohta M, Seto M, Ijichi H, Miyabayashi K, Kudo Y, Mohri D, Asaoka Y, Tada M, Tanaka Y, Ikenoue T, Kanai F, Kawabe T and Omata M: Decreased expression of the RAS-GTPase activating protein RASAL1 is associated with colorectal tumor progression. Gastroenterology 136: 206-216, 2009.

27 Dvorak HF: Tumors: wounds that do not heal. Similarities between tumor stroma generation and wound healing. N Engl J Med 315: 1650-9-1659, 1986.

28 Meng X, Nikolic-Paterson DJ and Lan HY: TGF- $\beta$ : The master regulator of fibrosis. Nat Rev Nephrol 12: 325-338, 2016.

29 Meng X, Tang PM, Li J and Lan HY: TGF- $\beta /$ Smad signaling in renal fibrosis. Front Physiol 6: 82, 2015.

30 Hill CS: Transcriptional control by the SMADs. Cold Spring Harb Perspect Biol, 2016. doi: 10.1101/cshperspect.a022079. [Epub ahead of print]

31 Massagué J: TGF $\beta$ signalling in context. Nat Rev Mol Cell Biol 13: 616-630, 2012.

32 Morikawa M, Derynck R and Miyazono K: TGF- $\beta$ and the TGF- $\beta$ Family: Context-dependent roles in cell and tissue physiology. Cold Spring Harb Perspect Biol 8: a021873, 2016.

33 Gjaltema RAF, de Rond S, Rots MG and Bank RA: Procollagen lysyl hydroxylase 2 expression is regulated by an alternative downstream transforming growth factor $\beta-1$ activation mechanism. J Biol Chem 290: 28465-76-28476, 2015.

34 van der Slot, AJ, Zuurmond A, Bardoel AFJ, Wijmenga C, Pruijs HEH, Sillence DO, Brinckmann J, Abraham DJ, Black CM, Verzijl N, DeGroot J, Hanemaaijer R, TeKoppele JM, Huizinga TWJ and Bank RA: Identification of PLOD2 as telopeptide lysyl hydroxylase, an important enzyme in fibrosis. J Biol Chem 278: 40967-40972, 2003.

35 Hinz B: Myofibroblasts. Exp Eye Res 142: 56-70, 2016.

36 Boak AM, Roy R, Berk J, Taylor L, Polgar P, Goldstein RH and Kagan HM: Regulation of lysyl oxidase expression in lung fibroblasts by transforming growth factor-beta 1 and prostaglandin E2. Am J Res Cell Mol Biol 11: 751-755, 1994.

37 Xie J, Wang C, Huang D, Zhang Y, Xu J, Kolesnikov SS, Sung KLP and Zhao H: TGF-betal induces the different expressions of lysyl oxidases and matrix metalloproteinases in anterior cruciate ligament and medial collateral ligament fibroblasts after mechanical injury. J Biomech 46: 890-898, 2013.

38 Lucero HA and Kagan HM: Lysyl oxidase: An oxidative enzyme and effector of cell function. Cell Mol Life Sci 63: 2304-2316, 2006.

39 Pan X, Chen Z, Huang R, Yao Y and Ma G: Transforming growth factor $\beta 1$ induces the expression of collagen type I by DNA methylation in cardiac fibroblasts. PLOS ONE 8: e60335e60343, 2013.

40 Zhao J, Shi W, Wang Y, Chen H, Bringas P Jr., Datto MB, Frederick JP, Wang X and Warburton D: Smad3 deficiency attenuates bleomycin-induced pulmonary fibrosis in mice.Am J Physiol 282: L585-L593, 2002

41 Evans RA, Tian YC, Steadman R and Phillips AO: TGF-beta1mediated fibroblast-myofibroblast terminal differentiation. The role of Smad proteins. Exp Cell Res 282: 90-100, 2003.

42 Harris WT, Kelly DR, Zhou Y, Wang D, Macewen M, Hagood JS, Clancy JP, Ambalavanan N and Sorscher EJ: Myofibroblast differentiation and enhanced TGF-B signaling in cystic fibrosis lung disease. PLOS ONE 8: e70196, 2013. 
$43 \mathrm{Hu} \mathrm{B}, \mathrm{Wu} \mathrm{Z}$ and Phan SH: Smad3 mediates transforming growth factor- $\beta$-induced $\alpha$-smooth muscle actin expression. Am J Respir Cell Mol Biol 29: 397-404, 2003.

44 Rønnov-Jessen L and Petersen OW: Induction of alphasmooth muscle actin by transforming growth factor-beta 1 in quiescent human breast gland fibroblasts. Implications for myofibroblast generation in breast neoplasia. Lab Invest 68 : 696-707, 1993.

45 Pattanaik D, Brown M, Postlethwaite BC and Postlethwaite AE: Pathogenesis of systemic sclerosis. Front Immunol 6: 272-312, 2015.

46 Tao Q, Wang B, Zheng Y, Jiang X, Pan Z and Ren J: Vitamin D prevents the intestinal fibrosis via induction of vitamin D receptor and inhibition of transforming growth factorbeta1/Smad3 pathway. Dig Dis Sci 60: 868-875, 2015.

47 Potter JJ, Liu X, Koteish A and Mezey E: 1,25-dihydroxyvitamin $\mathrm{D}_{3}$ and its nuclear receptor repress human $\alpha 1$ (I) collagen expression and type I collagen formation. Liver Int 33: 677-686, 2013.

48 Lichtler A, Stover ML, Angilly J, Kream B and Rowe DW: Isolation and characterization of the rat alpha 1(I) collagen promoter. Regulation by 1,25-dihydroxyvitamin D. J Biol Chem 264: 3072-3077, 1989.

49 Puche JE, Saiman Y and Friedman SL: Hepatic stellate cells and liver fibrosis. Compr Physiol 3: 1473-1492, 2013.

50 Hellerbrand C: Hepatic stellate cells - the pericytes in the liver. Pflügers Arch 465: 775-778, 2013.

51 Ding N, Yu RT, Subramaniam N, Sherman MH, Wilson C, Rao R, Leblanc M, Coulter S, He M, Scott C, Lau SL, Atkins AR, Barish GD, Gunton JE, Liddle C, Downes M and Evans RM: A Vitamin D receptor/SMAD genomic circuit gates hepatic fibrotic response. Cell 153: 601-613, 2013.

52 Kouzarides T: Chromatin modifications and their function. Cell 128: 693-705, 2007.

53 Bhattacharyya S, Ghosh AK, Pannu J, Mori Y, Takagawa S, Chen G, Trojanowska M, Gilliam AC and Varga J: Fibroblast expression of the coactivator p300 governs the intensity of profibrotic response to transforming growth factor beta. Arthritis Rheum 52: 1248-1258, 2005.

54 Ghosh AK and Varga J: The transcriptional coactivator and acetyltransferase p300 in fibroblast biology and fibrosis. J Cell Physiol 213: 663-671, 2007.

55 Abramovitch S, Dahan-Bachar L, Sharvit E, Weisman Y, Ben Tov A, Brazowski E and Reif S: Vitamin D inhibits proliferation and profibrotic marker expression in hepatic stellate cells and decreases thioacetamide-induced liver fibrosis in rats. Gut 60 1728-1737, 2011

56 Long MD, Sucheston-Campbell LE and Campbell MJ: Vitamin D receptor and RXR in the post-genomic era. J Cell Physiol 230: 758-766, 2015.

57 Christakos S, Dhawan P, Verstuyf A, Verlinden L and Carmeliet G: Vitamin D: Metabolism, molecular mechanism of action, and pleiotropic effects. Physiol Rev 96: 365-408, 2016.

58 Pike JW, Meyer MB, Benkusky NA and Shamsuzzaman S: Genomic determinants of vitamin D-regulated gene expression. Vitam Horm 100: 21-44, 2016.

59 Carlberg C: What do we learn from the genome-wide perspective on vitamin D3?. Anticancer Res 35: 1143-1151, 2015.

60 Carlberg C and Molnár F: Vitamin D receptor signaling and its therapeutic implications: Genome-wide and structural view. Can J Physiol Pharmacol 93: 311-318, 2015.
61 Krishnan AV and Feldman D: Mechanisms of the anti-cancer and anti-inflammatory actions of vitamin D. Annu Rev Pharmacol Toxicol 51: 311-336, 2011.

62 Cohen-Lahav M, Shany S, Tobvin D, Chaimovitz C and Douvdevani A: Vitamin D decreases NFkB activity by increasing IkB $\alpha$ levels. Nephrol Dial Transplant 21: 889-897, 2006.

63 Belochitski O, Ariad S, Shany S, Fridman V and Gavrilov V: Efficient dual treatment of the hormone-refractory prostate cancer cell line DU145 with cetuximab and 1,25-dihydroxyvitamin D3. In Vivo 21: 371-376, 2007.

64 Larriba MJ, González-Sancho JM, Barbáchano A, Niell N, Ferrer-Mayorga G and Muñoz A: Vitamin D is a multilevel repressor of $w n t / \beta$-catenin signaling in cancer cells. Cancers 5 : 1242-1260, 2013.

65 Ding N, Liddle C, Evans RM and Downes M: Hepatic actions of vitamin $\mathrm{D}$ receptor ligands: A sunshine option for chronic liver disease? Expert Rev Clin Pharmacol 6: 597-599, 2013.

66 Barish GD, Yu RT, Karunasiri M, Ocampo CB, Dixon J, Benner C, Dent AL, Tangirala RK and Evans RM: Bcl-6 and NF-kB cistromes mediate opposing regulation of the innate immune response. Genes Dev 24: 2760-2765, 2010.

67 Zerr P, Vollath S, Palumbo-Zerr K, Tomcik M, Huang J, Distler A, Beyer C, Dees C, Gela K, Distler O, Schett G and Distler JHW: Vitamin D receptor regulates TGF- $\beta$ signalling in systemic sclerosis. Ann Rheum Dis 74: e20, 2015.

68 Meredith A, Boroomand S, Carthy J, Luo Z and McManus B: 1,25 dihydroxyvitamine $\mathrm{D}_{3}$ inhibits TGF $\beta 1$-mediated primary human cardiac myofibroblast activation. PLoS ONE 10: e0128655, 2015.

69 Lee YA, Wallace MC and Friedman SL: Pathobiology of liver fibrosis: A translational success story. Gut 64: 830-841, 2015.

70 Sherman MH, Yu RT, Engle DD, Ding N, Atkins AR, Tiriac H, Collisson EA, Connor F, Van Dyke T, Kozlov S, Martin P, Tseng TW, Dawson DW, Donahue TR, Masamune A, Shimosegawa T, Apte MV, Wilson JS, Ng B, Lau SL, Gunton JE, Wahl GM, Hunter T, Drebin JA, O'Dwyer PJ, Liddle C and Tuveson DA: Vitamin D receptor-mediated stromal reprogramming suppresses pancreatitis and enhances pancreatic cancer therapy. Cell 159: 80-93, 2014

71 Hah N, Sherman MH, Yu RT, Downes M and Evans RM: Targeting transcriptional and epigenetic reprogramming in stromal cells in fibrosis and cancer. Cold Spring Harb Symp Quant Biol 80: 249-255, 2015.

72 Grady WM, Rajput A, Myeroff L, Liu DF, Kwon K, Willis J and Markowitz S: Mutation of the type II transforming growth factorbeta receptor is coincident with the transformation of human colon adenomas to malignant carcinomas. Cancer Res 58: 31013104, 1998.

73 Lampropoulos P, Zizi-Sermpetzoglou A, Rizos S, Kostakis A, Nikiteas $\mathrm{N}$ and Papavassiliou AG: TGF-beta signalling in colon carcinogenesis. Cancer Lett 314: 1-7, 2012.

74 Jakowlew SB: Transforming growth factor-beta in cancer and metastasis. Cancer Metastasis Rev 25: 435-457, 2006.

75 Calon A, Espinet E, Palomo-Ponce S, Tauriello DVF, Iglesias M, Cespedes MV, Sevillano M, Nadal C, Jung P, Zhang XH-, Byrom D, Riera A, Rossell D, Mangues R, Massagué J, Sancho E and Batlle E: Dependency of colorectal cancer on a TGF-b-driven program in stromal cells for metastasis initiation. Cancer Cell 22: 571-584, 2012

76 Kojima Y, Acar A, Eaton EN, Mellody KT, Scheel C, Ben-Porath I, Onder TT, Wang ZC, Richardson AL, Weinberg RA and Orimo 
A: Autocrine TGF-beta and stromal cell-derived factor-1 (SDF1) signaling drives the evolution of tumor-promoting mammary stromal myofibroblasts. PNAS 107: 20009-20014, 2010.

77 Calon A, Taurielloa DVF and Batlle E: TGF-beta in CAF-mediated tumor growth and metastasis. Semin Cancer Biol 25: 15-22, 2014.

78 Calon A, Lonardo E, Berenguer-Llergo A, Espinet E, HernandoMomblona X, Iglesias $\mathrm{M}$, Sevillano $\mathrm{M}$, Palomo-Ponce S, Tauriello DVF, Byrom D, Cortina C, Morral C, Barceló C, Tosi S, Riera A, Attolini CS, Rossell D, Sancho E and Batlle E: Stromal gene expression defines poor-prognosis subtypes in colorectal cancer. Nat Genet 47: 320-329, 2015.

79 Isella C, Terrasi A, Bellomo SE, Petti C, Galatola G, Muratore A, Mellano A, Senetta R, Cassenti A, Sonetto C, Inghirami G, Trusolino L, Fekete Z, Ridder MD, Cassoni P, Storme G, Bertotti A and Medico E: Stromal contribution to the colorectal cancer transcriptome. Nat Genet 47: 312-319, 2015.

80 Xia X, Wu W, Huang C, Cen G, Jiang T, Cao J, Huang K and Qiu Z: SMAD4 and its role in pancreatic cancer. Tumour Biol 36: 111-119, 2015

81 Mokady E, Schwartz B, Shany S and Lamprecht SA: A protective role of dietary vitamin $\mathrm{D}_{3}$ in rat colon carcinogenesis. Nutr Cancer 38: 65-73, 2000.

82 Mohr SB, Gorham ED, Kim J, Hofflich H, Cuomo RE and Garland CF: Could vitamin D sufficiency improve the survival of colorectal cancer patients? J Steroid Biochem Mol Biol 148: 239-244, 2015.

83 Klampfer L: Vitamin D and colon cancer. World J Gastrointest Oncol 6: 430-437, 2014.

84 Pereira F, Larriba MJ and Muñoz A: Vitamin D and colon cancer. Endocr Relat Cancer 19: R51-R71, 2012.

85 Ferrer-Mayorga G, Gómez-López G, Barbáchano A, FernándezBarral A, Peña C, Pisano DG, Cantero R, Rojo F, Muñoz A and Larriba MJ: Vitamin D receptor expression and associated gene signature in tumour stromal fibroblasts predict clinical outcome in colorectal cancer. Gut April, 2016. doi: 10.1136/gutjnl-2015310977. [Epub ahead of print]

86 Abu-Remaileh M, Bender S, Raddatz G, Ansari I, Cohen D, Gutekunst J, Musch T, Linhart H, Breiling A, Pikarsky E, Bergman Y and Lyko F: Chronic inflammation induces a novel epigenetic program that is conserved in intestinal adenomas and in colorectal cancer. Cancer Res 75: 2120-2130, 2015.

87 Quail DF and Joyce JA: Microenvironmental regulation of tumor progression and metastasis. Nat Med 19: 1423-1437, 2013.

88 Grivennikov SI, Greten FR and Karin M: Immunity, inflammation, and cancer. Cell 140: 883-899, 2010.

89 Chiba T, Marusawa H and Ushijima T: Inflammation-Associated Cancer Development in Digestive Organs: Mechanisms and roles for genetic and epigenetic modulation. Gastroenterology 143: 550-563, 2012.

90 Landskron G, De la Fuente M, Thuwajit P, Thuwajit C and Hermoso MA: Chronic inflammation and cytokines in the tumor microenvironment. J Immunol Res 2014: 149185, 2014.

91 Nathan C and Ding A: Nonresolving inflammation. Cell 140: 871-882, 2010.

92 Romano M, de Francesco F, Zarantonello L, Ruffolo C, Ferraro GA, Zanus G, Giordano A, Bassi N and Cillo U: From inflammation to cancer in inflammatory bowel disease: Molecular perspectives. Anticancer Res 36: 1447-1460, 2016.

93 Katanov C, Lerrer S, Liubomirski Y, Leider-Trejo L, Meshel T, Bar J, Feniger-Barish R, Kamer I, Soria-Artzi G, Kahani H, Banerjee
D and Ben-Baruch A: Regulation of the inflammatory profile of stromal cells in human breast cancer: Prominent roles for TNF- $\alpha$ and the NF-kB pathway. Stem Cell Res Ther 6: 87, 2015.

94 Raz Y and Erez N: An inflammatory vicious cycle: Fibroblasts and immune cell recruitment in cancer. Exp Cell Res 319: 1596$1603,2013$.

95 Servais C and Erez N: From sentinel cells to inflammatory culprits: Cancer-associated fibroblasts in tumour-related inflammation. Pathology 229: 198-207, 2013.

96 Erez N, Truitt M, Olson P and Hanahan D: Cancer-associated fibroblasts are activated in incipient neoplasia to orchestrate tumor-promoting inflammation in an NF-kB-dependent manner. Cancer Cell 17: 135-147, 2010.

97 Erez N, Glanz S, Raz Y, Avivi C and Barshack I: Cancerassociated fibroblasts express pro-inflammatory factors in human breast and ovarian tumors. Biochem Biophys Res Commun 437: 397-402, 2013.

98 Mitchell S, Vargas J and Hoffmann A: Signaling via the NFKB system. Wiley Interdiscip Rev Syst Biol Med 8: 227-241, 2016.

99 Wöbke TK, Sorg BL and Steinhilber D: Vitamin D in inflammatory diseases. Front Physiol 5: 2014.

100 Sun J, Kong J, Duan Y, Szeto FL, Liao A, Madara JL and Li YC: Increased NF-kappaB activity in fibroblasts lacking the vitamin D receptor. Am J Physiol Endocrinol Metab 291: E315-E322, 2006.

101 Szeto FL, Sun J, Kong J, Duan Y, Liao A, Madara JL and Li YC: Involvement of the vitamin $\mathrm{D}$ receptor in the regulation of NF$\mathrm{KB}$ activity in fibroblasts. J Steroid Biochem Mol Biol 103: $563-$ 566, 2007.

102 Holohan C, Van Schaeybroeck S, Longley DB and Johnston PG: Cancer drug resistance: An evolving paradigm. Nat Rev Cancer 13: 714-726, 2013.

103 Klemm F and Joyce JA: Microenvironmental regulation of therapeutic response in cancer. Trends Cell Biol 25: 198-213, 2015.

104 Gkretsi V, Stylianou A, Papageorgis P, Polydorou C and Stylianopoulos T: Remodeling components of the tumor microenvironment to enhance cancer therapy. Front Oncol 5: 214, 2015.

105 Whatcott CJ, Hanl H and Von Hoff DD: Orchestrating the tumor microenvironment to improve survival for patients with pancreatic cancer normalization, not destruction. Cancer J 21: 299-306, 2015.

106 Rowley DR: Reprogramming the tumor stroma: A new paradigm. Cancer Cell 26: 451-452, 2014.

107 Froeling FEM and Kocher HM: Homeostatic restoration of desmoplastic stroma rather than its ablation slows pancreatic cancer progression. Gastroenterology 148: 849-850, 2015.

108 Provenzano PP, Cuevas C, Chang AE, Goel VK, Von Hoff DD and Hingorani SR: Enzymatic targeting of the stroma ablates physical barriers to treatment of pancreatic ductal adenocarcinoma. Cancer Cell 21: 418-429, 2012.

109 Tan MCB, Goedegebuure PS, Belt BA, Flaherty B, Sankpal N, Gillanders WE, Eberlein TJ, Hsieh $\mathrm{C}$ and Linehan DC: Disruption of CCR5-dependent homing of regulatory T cells inhibits tumor growth in a murine model of pancreatic cancer. $\mathrm{J}$ Immunol 182: 1746-55-1755, 2009.

110 Lipkin M and Lamprecht SA. Mechanism of action of vitamin D: Recent findings and new questions. J Med Food 9: 135-137, 2006.

Received September 14, 2016

Revised September 27, 2016

Accepted September 28, 2016 